\title{
AS AÇÕES DE GOVERNO E A GOVERNANÇA FLORESTAL NO PARANÁ
}

\author{
Renê Galiciolli1 ${ }^{1}$, Anadalvo Juazeiro dos Santos², Vitor Afonso Hoeflich ${ }^{3}$ \\ 1Economista, UFPR, Curitiba, PR, Brasil - rene@galicioli.com.br \\ ${ }^{2}$ Eng. Florestal, Dr., Depto. Economia Rural e Extensão, UFPR, Curitiba, PR, Brasil - ajsantos@ufpr.br \\ ${ }^{3}$ Eng. Agrônomo, Dr., Depto. de Economia Rural e Extensão, UFPR, Curitiba, PR, Brasil - hoeflich@ufpr.br \\ Recebido para publicação: 29/10/2013 - Aceito para publicação: 01/03/2014
}

\begin{abstract}
Resumo
Governança florestal é tema de relevância entre as mais importantes organizações internacionais, como a Organização das Nações Unidas para Agricultura e Alimentação (FAO), a Organização para Cooperação e Desenvolvimento Econômico (OECD) e o Banco Mundial que, de forma convergente, defendem a importância das florestas no equilíbrio físico, econômico e cultural e a necessidade de sua conservação e utilização sensata. Essas organizações desenvolvem e testam indicadores de governança florestal discutindo sobre governança das florestas e de desenvolvimento florestal. O presente artigo objetiva analisar a percepção dos atores sociais do setor florestal paranaense acerca da governança florestal, tomando-se como referência um "modelo" de análise adotado pela OECD (2005). Como instrumento metodológico, adaptou-se o modelo de questionário desenvolvido pela OECD, aplicado então aos atores sociais envolvidos na gestão florestal do Paraná, que foram indagados sobre governança florestal. O estudo teve como referencial teórico o quadro desenvolvido pela FAO (2011), em que se determinam três pilares de boa governança florestal: a política legal regulamentar, o planejamento e tomada de decisões e a implementação dos processos de políticas florestais.

Palavras-chave: Governo do Paraná; governança florestal; FAO.
\end{abstract}

\begin{abstract}
The government actions and forest governance in Paraná. Forest governance is a matter of relevance among the most important international organizations like the United Nations Food and Agriculture Organization (FAO), the Organization for Economic Cooperation and Development (OECD) and the World Bank. Such organizations, in a convergent way, advocate the importance of forests in physical, economic and cultural balance as well as the need for their conservation and wise use. These organizations develop and test indicators of forest governance discussing forests governance and development. This article aims to analyze the perception of social actors in the forest sector in Paraná on forest governance, taking as reference a "model" analysis adopted by the OECD (2005). As a methodological tool, we adapted the questionnaire model developed by the OECD, then applied it to the social actors involved in forest management in Paraná, who were asked about forest governance. The study had as theoretical bases the framework developed by FAO (2011) which determines three pillars of good forest governance: legal policy regulations; planning and decision-making processes and implementation of forest policies.
\end{abstract}

Keywords: Government of Paraná; forest; FAO.

\section{INTRODUÇÃO}

Para o Banco Mundial (1992), as florestas e os produtos florestais exercem importante função no desenvolvimento econômico mundial e na preservação ambiental. Além da produção de matéria-prima para importantes e estratégicos segmentos da economia mundial, as florestas são imprescindíveis ao equilíbrio do meio ambiente. Para o Banco Mundial, o problema geral de governança é "a falta do exercício da autoridade, controle, administração e poder de governo". Destaca também que a má gestão dos recursos florestais é tema de interesse de organizações internacionais.

O projeto da Iniciativa para a Governança Florestal (GFI, 2009) entende que, quando o governo assume a responsabilidade pela tomada de decisões e quando os atores sociais e intervenientes não 
governamentais também assumem suas responsabilidades, existe a possibilidade de melhor gestão dos recursos florestais.

A Organização das Nações Unidas para a Agricultura e Alimentação (FAO, 2005) manifesta a sua convicção de que a floresta é um fator de importância primordial no equilíbrio econômico, social e físico do mundo e que há necessidade de conservação e utilização sensata das florestas.

A Organização para Cooperação e Desenvolvimento Econômico (OECD, 2005) realizou estudos sobre a governança no setor público que comprovam que a forma de gestão de imposição da responsabilidade pública proporciona o desenvolvimento, fundamentando-se nos princípios da liderança, do compromisso, da responsabilidade, da transparência e da integridade.

Segundo a FAO (2011), a criação de um quadro global de análise para diagnosticar, avaliar e monitorar a governança das florestas é amplamente aceita entre os atores florestais. A qualidade da governança muitas vezes determina se os recursos florestais são utilizados de forma eficiente, sustentável e equitativa e se os países tendem a alcançar as metas relacionadas com o desenvolvimento da floresta. A FAO elaborou esse quadro indicando os princípios e pilares de boa governança, que facilita a descrição, o diagnóstico, o acompanhamento, a avaliação e a elaboração de relatórios sobre o estado da governança no setor florestal de um país.

Justifica-se este estudo com base na afirmação do Centro de Economia Florestal Aplicada (CEFA/UFPR, 2007) de que, apesar da importância do Setor Florestal do Paraná (do ponto de vista econômico, social e ambiental), a base florestal existente hoje no Paraná não é suficiente para o crescimento da indústria madeireira. Para o CEFA/UFPR, atualmente, o consumo de madeira em tora é superior à capacidade produtiva e tem sua matéria-prima oriunda de reflorestamentos com produção inferior ao consumo da indústria.

O Fórum "Futuro 10 Paraná," apontou a degradação ambiental e a utilização dos recursos florestais de forma predatória como dois dos principais problemas da sociedade paranaense nos dias atuais. No painel florestal, discutido nesse fórum, foi afirmado que não existe e nem foi proposta, nos últimos anos, uma estruturação clara dos procedimentos a serem adotados para efetivar os instrumentos da política florestal no estado do Paraná. Os planos relacionados ao incremento das áreas reflorestadas, tanto para recuperação de áreas degradadas como para fomento, ou ainda para atender à demanda industrial ou outra demanda, como a energética, não têm sido implementados e nem sequer receberam, nos últimos anos, qualquer atenção por parte do governo estadual.

O Banco Mundial (1992) define governança como "a maneira pela qual o poder é exercido na administração dos recursos econômicos e sociais do país, com vistas ao desenvolvimento".

Santos (1996) defende que a boa governança passa a ser requisito indispensável de um desenvolvimento sustentado, que incorpora ao crescimento econômico equidade social e direitos humanos.

Araújo (2002), ao abordar os conceitos de governança e governabilidade, discorre sobre os pensamentos de autores diferentes e conclui que é consensual entre eles que as variáveis de governabilidade e de governança mantêm entre si uma relação muito forte, uma vez que são tipologias convergentes e trazem mais semelhanças do que diferenças.

Kissler (2006) defende que, sob a ótica da ciência política, a governança pública está associada a uma mudança na gestão política. Trata-se de uma tendência para se recorrer cada vez mais à autogestão nos campos social, econômico e político e para nova composição de formas de gestão daí decorrentes.

É nesse contexto que o presente artigo objetiva analisar a percepção dos atores sociais do setor florestal paranaense sobre governança florestal, caracterizando de forma específica as ações de governo e a governança florestal no estado do Paraná.

\section{METODOLOGIA}

\section{Governança florestal}

Segundo GFI (2009), para obter uma definição de boa governança florestal, primeiramente, o governo tem de estar envolvido no processo de tomadas das decisões. Em segundo lugar, os atores sociais e intervenientes fora do governo, mas envolvidos com o setor florestal, devem participar ativamente da governança.

\footnotetext{
${ }^{1}$ O Fórum Futuro 10 Paraná reuniu, no ano de 2005, as principais lideranças empresariais, sociais e políticas para discutir e apresentar um plano estratégico integrado para o desenvolvimento do Estado. Para garantir a representatividade, o Fórum foi realizado em 8 cidades-polo do Paraná, onde foram debatidos temas importantes para o Estado.
} 
Para a FAO (2011), governança florestal é considerada adequada se é caracterizada por participação das partes interessadas, transparência do processo decisório, responsabilização de atores sociais e respeito à legislação e previsibilidade da tomada de decisões. Boa governança também está associada à gestão eficiente e eficaz dos recursos naturais, humanos, financeiros e alocação equitativa de recursos e benefícios.

A FAO (2011) desenvolveu um quadro baseado no entendimento de que a governança é o contexto e o produto da interação de uma série de atores sociais e intervenientes com interesses diversos geralmente aceitos de governança florestal.

Ainda para a FAO (2011), a tabela 1 pode identificar ações necessárias para monitorar fluxos financeiros no setor florestal e divisão equitativa dos benefícios. Segundo a organização, a gestão das florestas é essencial para combater as alterações climáticas, e o quadro apresenta alternativas para que esse manejo florestal sustentável seja apropriadamente implantado e administrado.

Tabela 1. Princípios e pilares de boa governança florestal.

Table 1. Principles and pillars of good forest governance.

\begin{tabular}{lccc}
\hline \multirow{2}{*}{ Princípios } & \multicolumn{3}{c}{ Pilares de boa governança } \\
\cline { 2 - 4 } & $\mathbf{1}$ & $\mathbf{2}$ & $\mathbf{3}$ \\
\hline Responsabilidade & & & \\
Eficácia & & & \\
Eficiência & Política, legal, & Planejamento e tomada de decisão & $\begin{array}{c}\text { Implementação, aplicação e } \\
\text { conformidade dos processos } \\
\text { Legalidade }\end{array}$ \\
Participação & institucional & nos processos florestais & florestais \\
Transparência & & & \\
\hline Fonte: FAO (2011). Adaptado pelos autores. & &
\end{tabular}

\section{Política florestal}

Para Grön (1947), a expressão política florestal é a soma de medidas tomadas pelo Estado para preservar o interesse público em relação às florestas e silvicultura. Pode haver disparidade entre os interesses privados e os públicos no setor florestal, devido ao fato de que a utilidade da floresta para o proprietário individual pode ser diferente do interesse coletivo.

Segundo a FAO (1951), os princípios que regem a formulação e execução de uma política florestal são os seguintes:

I - cada país deve determinar e reservar áreas para serem dedicadas às florestas;

II - cada país deverá aplicar as melhores técnicas viáveis na busca de derivar em perpetuidade, para o maior número dos seus habitantes, o máximo de benefícios disponíveis a partir dos valores de proteção, produtivos e acessórios de suas florestas. Isso implica que:

a) a proteção deve ser conferida contra danos ou destruição por homem ou por causas como o fogo, insetos e doenças da árvore;

b) a produção deve ser organizada, em quantidade e qualidade, com vista à obtenção de pelo menos um rendimento sustentado. Logo que possível, deve ser considerado, em primeiro lugar, qualquer papel protetor atribuído à floresta e, em seguida, quaisquer outros interesses, em nível mundial, regional, nacional ou local, a que a floresta possa servir;

c) os métodos econômicos e racionais de exploração florestal e de transformação e utilização dos seus produtos devem ser incentivados, de modo que o volume e a variedade de produtos obtidos a partir da matéria-prima fornecida pela floresta possam ser aumentados até ao máximo possível;

III - conhecimento adequado de todos os aspectos dos recursos florestais - silvicultura, consumo e utilização de produtos florestais - é indispensável. Isso inclui, em graus variados nas diferentes fases do desenvolvimento da política florestal, conhecimento dos recursos disponíveis em terras florestadas ou daqueles que devem ser disponibilizados em terras ociosas; das necessidades nacionais de produtos florestais; das leis naturais aplicáveis às florestas e das técnicas empregadas na produção de plantações florestais e para a sua utilização;

IV - consciência pública de valores da floresta que deveriam ser desenvolvidos por todos os meios possíveis; 
V - a legislação florestal para a aplicação da política florestal deve ser promulgada em consonância com as formas jurídicas e os costumes do país;

VI - o serviço florestal deve ser estabelecido com pessoal qualificado em todas as dimensões, para desenvolver e implementar a política florestal, em colaboração com as organizações adequadas que possam existir, inclusive para administrar a legislação florestal;

VII - formação adequada para todos os envolvidos com a gestão de florestas ou a utilização e transformação de produtos florestais.

Para Merlo e Paveri (1997), a política florestal é uma disposição geral do conjunto de instrumentos, sendo divididos em instrumentos obrigatórios e voluntários. Os instrumentos de política obrigatórios são:

a) ferramentas essenciais juridicamente vinculativas que foram, são e serão parte essencial de qualquer pacote de política florestal. Sua adoção deve ser cuidadosamente avaliada, para evitar políticas irrealistas;

b) instrumentos econômico-financeiros. Os instrumentos de política florestal representam um ponto crucial de muitas políticas e enfatizam a importância de escolher não só aqueles instrumentos de política que são mais apropriados para resolver um problema em determinado contexto, mas também dar a devida atenção ao equilíbrio que deve existir entre os diversos instrumentos, para alcançar a ótima combinação de instrumentos de política;

c) instrumentos para o mercado e estratégias de marketing relacionadas, que devem ser estudados e apoiados por novas políticas e instituições.

\section{Base de dados}

Para realizar a pesquisa sobre a governança florestal do Paraná, foi elaborado um questionário contendo questões objetivas e subjetivas, de acordo com as orientações de governança pública da OECD (2005).

O questionário foi aplicado a diversos atores sociais envolvidos nas questões florestais do estado do Paraná, entre servidores públicos, empresários, profissionais e acadêmicos identificados por sua experiência e atuação na gestão de recursos florestais. Entre os entrevistados, 60 atores sociais responderam o questionário de forma satisfatória, material utilizado neste trabalho.

Para tanto, foram selecionados e entrevistados representantes do Governo Municipal, entre autoridades públicas de municípios que possuem vocação no setor florestal, seja no cultivo e na preservação, seja na industrialização da madeira.

Entre os representantes do Governo Estadual, foram entrevistados secretários estaduais, presidentes, diretores e técnicos de autarquias e institutos estaduais. Entre os atores sociais representantes do Governo Federal, foram entrevistados presidentes, diretores e técnicos de autarquias e institutos federais que efetivamente atuam nas questões florestais do estado do Paraná.

Os atores sociais representantes das ONGS entrevistados representam associações de defesa do meio ambiente, gestores e técnicos de organizações que assessoram, apoiam ou defendem as questões florestais no estado do Paraná.

Entre os atores sociais representantes das empresas privadas, foram entrevistados diretores e gestores de indústrias beneficiadoras de madeiras, produtores de bens e artefatos de madeira, empresas de consultoria de apoio ao setor florestal, produtores de mudas e sementes e empresas de reflorestamento. No setor acadêmico, foram entrevistados professores doutores e mestres, doutorandos e pesquisadores na área florestal e ambiental.

Os atores sociais receberam o questionário por meio eletrônico ou de entrevistas pessoais, no período de setembro de 2010 a março de 2011.

\section{Operacionalização da metodologia}

A pesquisa qualitativa foi usada procurando entender detalhadamente o que os entrevistados pensam sobre as questões florestais do estado do Paraná, identificando a extensão total de respostas ou opiniões desses atores sociais. Ao invés da utilização de procedimentos estatísticos, esta pesquisa qualitativa trabalhou com descrições, comparações e interpretações. Por esta pesquisa ser mais participativa e, portanto, menos controlável, os participantes puderam direcionar o rumo da pesquisa em suas interações com o pesquisador. Assim, a pesquisa visou descrever as características dos atores sociais e sua percepção sobre a 
governança florestal no Paraná. Envolveu o uso de técnicas padronizadas de coleta de dados (questionário e observação sistemática), assumindo, em geral, a forma de levantamento de dados.

Estruturou-se um grupo similar constituído por diversos atores sociais - representantes da sociedade civil organizada, representantes de usuários das florestas (ONGs, empresas privadas), representantes do setor acadêmico e representantes do poder público -, com a finalidade de evidenciar as percepções sobre a estrutura de governança dos órgãos gestores do setor florestal. Esse método produziu informações diferenciadas que enriqueceram o conhecimento científico acerca das questões de governança florestal no Paraná.

Como base teórica para a realização da pesquisa, foram utilizados os conceitos da FAO (2011), que elaborou um quadro global com pilares básicos de análise para diagnosticar, avaliar e monitorar florestas com sustentação em governança florestal de forma amplamente reconhecida entre os atores florestais, em que se defende que a ampla aceitação e análise abrangente do quadro irá facilitar os esforços dentro e entre países para a melhor governança florestal.

As respostas dadas pelos atores sociais no questionário foram adaptadas pelos autores, de acordo com as orientações de governança pública da $\operatorname{OECD}^{2}$ (2005), para o contexto da gestão estadual de recursos florestais. Identificando e analisando as dimensões e mecanismo da estrutura de governança na gestão de recursos florestais do estado do Paraná, tomou-se como parâmetro, porém adaptando-se, as orientações de governança pública da OECD, em função de que os autores entenderam ser a melhor base pesquisada sobre a temática.

$\mathrm{Na}$ caracterização das ações do Governo do Estado do Paraná, responsável pela gestão das florestas, pelos conceitos da OECD, além da interrogação direta dos entrevistados foi utilizada a pesquisa documental elaborada a partir de materiais que não receberam tratamento analítico, como plano e projetos governamentais, monografias e demais textos acadêmicos.

\section{RESULTADOS E DISCUSSÃO}

A grande maioria dos atores sociais entrevistados, representantes das ONGs, tem período de atuação em suas instituições inferior a 10 anos. No setor acadêmico, os entrevistados têm atuação entre 5 e 15 anos em suas áreas.

Entre os atores sociais representantes do Governo Federal, o período de atuação nas suas instituições é superior a 10 anos de trabalho. Dentre os representantes do Governo Estadual, o tempo de atuação varia entre 05 e 15 anos. No Governo Municipal, os representantes entrevistados concentram-se com menos de 10 anos de atividade nas suas instituições. de atividade.

Entre os representantes das empresas privadas, a atuação no setor compreende entre 05 e 15 anos

A grande maioria dos atores sociais entrevistados, representantes das ONGS, tem formação acadêmica no curso de Administração, com demais representantes na formação em Engenharia Florestal, Economia, Direito e Assistência Social. No setor acadêmico, os entrevistados, em sua maioria, têm formação em Engenharia Florestal.

Entre os atores sociais representantes do Governo Federal e Estadual, a formação acadêmica dos entrevistados está concentrada em Engenharia Florestal e Agronomia. No Governo Municipal, os representantes entrevistados possuem formação acadêmica concentrada em Agronomia e Administração. Entre os atores sociais entrevistados representantes das empresas privadas, a formação acadêmica de sua maioria é a Engenharia Florestal.

Observa-se que, apesar de a maioria dos entrevistados possuírem a formação em Engenharia Florestal, há uma participação significativa de outros profissionais atuando no setor florestal, em especial engenheiros agrônomos, economistas, administradores e advogados.

Os resultados obtidos nas atividades previstas na política pública estadual relativa à gestão são apresentados a seguir.

\footnotetext{
${ }^{2}$ OECD. País Reforma, Brasília. Daniel Blume. Administrador Principal, Divulgação Latino-americanos. Mesa Redonda sobre Governança Corporativa Divisão de Assuntos Corporativos da OECD. 2005.
} 
Tabela 2. Percepção dos atores sociais entrevistados quanto à transparência do Governo do Estado do Paraná em relação à sua política florestal.

Table 2. Perception of social actors interviewed about the transparency of the Government of the State of Paraná in relation to its forestry policy.

\begin{tabular}{lccccccc}
\hline \multirow{2}{*}{ Atores sociais } & \multicolumn{2}{c}{ Discorda } & \multicolumn{2}{c}{ Concorda } & \multicolumn{2}{c}{ Concorda totalmente } & Total \\
\cline { 2 - 9 } & $\mathbf{N}^{\mathbf{0}}$ absoluto & $(\boldsymbol{\%})$ & $\mathbf{N}^{\mathbf{0}}$ absoluto & $\mathbf{( \% )}$ & $\mathbf{N}^{\mathbf{0}}$ absoluto & $\mathbf{( \% )}$ & $\mathbf{( \% )}$ \\
\hline Municipal & 3 & 30 & 6 & 60 & 1 & 10 & 100 \\
Estadual & 2 & 20 & 6 & 60 & 2 & 20 & 100 \\
Federal & 0 & 0 & 8 & 80 & 2 & 20 & 100 \\
ONGs & 6 & 60 & 4 & 40 & 0 & 0 & 100 \\
Empresas & 9 & 90 & 1 & 10 & 0 & 0 & 100 \\
Pesquisadores & 6 & 60 & 4 & 40 & 0 & 0 & 100 \\
\hline Total & 26 & 43 & 29 & 48 & 5 & 9 & 100 \\
\hline
\end{tabular}

Analisando a tabela 2, observa-se que o resultado do questionário mostra equilíbrio entre a totalidade das respostas, em que $43 \%$ discordam e $48 \%$ concordam que o Governo do Estado do Paraná estabelece quadro claro e transparente de sua política florestal. Os representantes dos Governos Municipal, Estadual e Federal responderam que o Governo do Estado do Paraná estabelece um quadro claro, coerente e transparente de sua política florestal. Os representantes de empresas privadas, das ONGs e pesquisadores foram enfáticos em responder de forma contrária aos demais entrevistados.

Os representantes do setor empresarial, ao opinarem sobre a transparência do Governo do Estado do Paraná em sua política florestal, assim se manifestaram:

"Faz-se necessário que o Poder Público se empenhe nas discussões de forma transparente para a criação das unidades de conservação."

"Importante que o Governo do Paraná discuta, de forma clara e transparente, com a sociedade civil a alocação de recursos florestais."

Os entrevistados, representantes do Governo Federal, assim opinaram:

"O Governo do Estado do Paraná estabelece um quadro claro, coerente e transparente de sua política florestal."

"O Paraná tem atuação forte no combate ao desmatamento e na manutenção de sua reserva legal, no entanto precisa de forma transparente levar esta discussão com os atores envolvidos no setor florestal"

Os entrevistados, representantes do setor acadêmico, assim opinaram:

"O Governo do Estado não estabelece discussão ampla $e$ transparente a sua politica para o setor."

"No Paraná, por não haver transparência governamental a política florestal faz parte de outros interesses maiores ou da questão agrícola ou da questão ambiental."

Analisando a tabela 3 quanto às Informações do Governo do Estado do Paraná sobre a implementação e gestão de sua Política Estadual de Florestas, $40 \%$ da totalidade dos entrevistados discordam e $47 \%$ concordam que as informações sobre a implementação da Política Estadual de Florestas são frequentemente apresentadas aos órgãos legislativos e à população em geral. Os representantes dos Governos Municipal, Estadual e Federal responderam que as informações são frequentemente apresentadas aos órgãos legislativos e à população em geral. Os representantes de empresas privadas e das ONGs foram enfáticos em responder que tais informações não são frequentemente apresentadas (Tabela 3).

Os entrevistados representantes das empresas, pesquisadores e ONGs enfatizaram:

"Há necessidade de publicidade e mais informações sobre as questões florestais no estado do Paraná."

"O Governo do Paraná, não informa adequadamente a população em geral sobre a política de educação ambiental."

Analisando a tabela 4, observa-se que a maioria dos entrevistados discorda que o Governo do Estado do Paraná permite a autonomia dos órgãos gestores em relação à implementação da Política Estadual de Florestas. Os representantes do Governo Estadual e Federal responderam que o Governo do 
Estado do Paraná permite essa autonomia, contudo, foram rebatidos pelos representantes do Governo Municipal, de empresas privadas, das ONGs e de pesquisadores (Tabela 4).

Tabela 3. Percepção dos atores sociais entrevistados quanto à apresentação pelo Governo do Estado do Paraná das informações sobre a implementação e gestão de sua Política Estadual de Florestas.

Table 3. Perception of social actors interviewed on the presentation by the Government of the State of Paraná information on the implementation and management of a State Policy on Forests.

\begin{tabular}{lccccccc}
\hline \multirow{2}{*}{ Atores sociais } & \multicolumn{2}{c}{ Discorda } & \multicolumn{2}{c}{ Concorda } & Concorda totalmente & Total \\
\cline { 2 - 8 } & $\mathbf{N}^{\mathbf{0}}$ absoluto & $\mathbf{( \% )}$ & $\mathbf{N}^{\mathbf{0}}$ absoluto & $\mathbf{( \% )}$ & $\mathbf{N}^{\mathbf{0}}$ absoluto & $\mathbf{( \% )}$ & $\mathbf{( \% )}$ \\
\hline Municipal & 2 & 20 & 6 & 60 & 2 & 20 & 100 \\
Estadual & 0 & 0 & 7 & 70 & 3 & 30 & 100 \\
Federal & 0 & 0 & 7 & 70 & 3 & 30 & 100 \\
ONGs & 7 & 70 & 3 & 30 & 0 & 0 & 100 \\
Empresas & 10 & 100 & 0 & 0 & 0 & 0 & 100 \\
Pesquisadores & 5 & 50 & 5 & 50 & 0 & 0 & 100 \\
\hline Total & 24 & 40 & 28 & 47 & 8 & 13 & 100 \\
\hline
\end{tabular}

Tabela 4. Participação dos atores sociais quanto ao grau de autonomia dos órgãos gestores das florestas em relação à implementação da Política Estadual de Florestas.

Table 4. Participation of social actors in relation to the autonomy degree of forest management agencies regarding the implementation of the State Policy on Forests.

\begin{tabular}{lccccccc}
\hline \multirow{2}{*}{ Atores sociais } & \multicolumn{2}{c}{ Discorda } & \multicolumn{2}{c}{ Concorda } & Concorda totalmente & Total \\
\cline { 2 - 8 } & $\mathbf{N}^{\mathbf{0}}$ absoluto & $\mathbf{( \% )}$ & $\mathbf{N}^{\mathbf{0}}$ absoluto & $\mathbf{( \% )}$ & $\mathbf{N}^{\mathbf{0}}$ absoluto & $\mathbf{( \% )}$ & $\mathbf{( \% )}$ \\
\hline Municipal & 7 & 70 & 3 & 30 & 0 & 0 & 100 \\
Estadual & 1 & 10 & 8 & 80 & 1 & 10 & 100 \\
Federal & 1 & 10 & 8 & 80 & 1 & 10 & 100 \\
ONGs & 9 & 90 & 1 & 10 & 0 & 0 & 100 \\
Empresas & 10 & 100 & 0 & 0 & 0 & 0 & 100 \\
Pesquisadores & 8 & 80 & 2 & 20 & 0 & 0 & 100 \\
\hline Total & 36 & 60 & 22 & 37 & 2 & 3 & 100 \\
\hline
\end{tabular}

Na opinião dos entrevistados, representantes do Governo Federal:

"O Governo do Estado do Paraná nunca se aparelhou institucionalmente, dando autonomia aos órgãos gestores e visando à descentralização da politica florestal."

"As principais responsabilidades de gestão do setor recaíram sobre a União, desobrigando o Governo Estadual de compromissos políticos com a questão florestal e com a administração dos recursos naturais."

Os entrevistados, representantes do Governo Municipal, assim opinaram:

"O Paraná não constituiu órgão florestal específico na sua estrutura administrativa, deixando aos seus órgãos ambientais elou agrícolas e ao Governo Federal a responsabilidade de administração do setor."

Os representantes das empresas, pesquisadores e ONGs assim se manifestaram:

"Tendo em vista a importância econômica, social e ecológica dos recursos florestais para o Paraná, incentivando a adesão da iniciativa privada, o Governo do Estado do Paraná deveria atribuir aos órgãos gestores a incumbência de formular políticas públicas que viessem ao interesse do setor."

"No Paraná os órgãos gestores não possuem autonomia para investir em pesquisa e valorizar o setor florestal desconsiderando sua importância econômica e social."

No que diz respeito à avaliação de desempenho dos órgãos gestores, os entrevistados discordam que o processo de avaliação de desempenho desses órgãos seja atendido por sistema de informações 
eficaz. Os representantes do Governo Estadual e Federal responderam que no Governo do Estado do Paraná o processo de avaliação de desempenho dos órgãos gestores é atendido por sistema de informações eficaz. Os representantes do Governo Municipal, de empresas privadas, das ONGS e pesquisadores, por sua vez, discordam (Tabela 5).

Tabela 5. Percepção dos atores sociais quanto à implementação e execução de política de avaliação de desempenho dos órgãos gestores da política florestal no estado do Paraná.

Table 5. Perception of social actors in in relation to implementation and execution of performance evaluation policy from the management bodies of forest policy in the state of Paraná.

\begin{tabular}{|c|c|c|c|c|c|c|c|}
\hline \multirow{2}{*}{ Atores sociais } & \multicolumn{2}{|c|}{ Discorda } & \multicolumn{2}{|c|}{ Concorda } & \multicolumn{2}{|c|}{ Concorda totalmente } & \multirow{2}{*}{$\begin{array}{l}\text { Total } \\
(\%)\end{array}$} \\
\hline & $\mathrm{N}^{\circ}$ absoluto & $(\%)$ & $\mathrm{N}^{\circ}$ absoluto & $(\%)$ & $\mathbf{N}^{0}$ absoluto & $(\%)$ & \\
\hline Municipal & 8 & 80 & 1 & 10 & 1 & 10 & 100 \\
\hline Estadual & 2 & 20 & 7 & 70 & 1 & 10 & 100 \\
\hline Federal & 3 & 30 & 6 & 60 & 1 & 10 & 100 \\
\hline ONGs & 10 & 100 & 0 & 0 & 0 & 0 & 100 \\
\hline Empresas & 10 & 100 & 0 & 0 & 0 & 0 & 100 \\
\hline Pesquisadores & 9 & 90 & 1 & 10 & 0 & 0 & 100 \\
\hline Total & 42 & 70 & 15 & 25 & 3 & 5 & 100 \\
\hline
\end{tabular}

Os entrevistados representantes do Poder Público Municipal assim opinaram:

"O uso da avaliação de desempenho como instrumento para o aperfeiçoamento da gestão governamental gera aumento da eficiência e a ampliação do controle social."

"A administração pública em todos os seus níveis deve adotar a política de avaliação de desempenho dos órgãos gestores atendendo de forma eficiente, rápida e satisfatória às demandas crescentes e diferenciadas vindas tanto da sociedade quanto de órgãos do próprio sistema."

Os representantes do setor privado emitiram a seguinte opinião:

"A sociedade tem exigido das instituições governamentais uma atuação mais próxima com a das organizações privadas, com avaliação de desempenho de seus colaboradores."

Os representantes do setor acadêmico assim opinaram:

"O processo de avaliação de desempenho dos órgãos públicos no Paraná não possui sistema de informações eficaz."

"No Governo do Estado do Paraná não há qualquer processo de avaliação de desempenho dos órgãos públicos que tenha resultado efetivo para o interesse público."

\section{CONCLUSÕES E RECOMENDAÇÕES}

- Com relação à responsabilidade do Governo do Estado do Paraná enquanto responsável pela gestão das florestas, conclui-se que ele não estabelece um quadro transparente na implementação de seus intrumentos de política florestal, não apresenta informações, não permite a autonomia de seus órgãos gestores e nem possui um efetivo acompanhamento de avaliação de desempenho.

- Essa conclusão se baseia na opinião expressiva dos atores não governamentais e não é a mesma opinião, na sua maioria, dos atores governamentais entrevistados. Os atores entrevistados que representam o governo consideram suas ações transparentes, diferentemente da opinião dos demais atores entrevistados.

- Na opinião dos autores e através das constatações de pesquisa, a diferença de opiniões se dá pela falta de transparência por parte do governo na implementação de suas políticas florestais, não apresentando informações acessíveis aos demais atores da sociedade e centralizando suas ações.

- Recomenda-se que o Governo do Estado do Paraná promova a inserção do setor florestal como prioridade nas suas políticas públicas, criando na estrutura administrativa do Governo do Estado um órgão próprio que trate especificamente das questões florestais nos aspectos relacionados à preservação, conservação e produção de bens e serviços, assim como a definição de estratégias e mecanismos gerenciais eficazes para o setor florestal. 


\section{REFERÊNCIAS}

ARAÚJO, V. de C. A conceituação de governabilidade e governança, da sua relação entre si e com o conjunto da reforma do Estado e do seu aparelho. Brasília: ENAP, 2002.

BANCO MUNDIAL. Framework for Assessing and Monitoring Forest Governance. The Program on Forests (Profor). Rome, 2011. Disponível em 〈http://www.fao.org〉. Acesso em: 16/06/2011.

Governance and Development. Washington D.C., 1992. Disponível em: <web.worldbank.org>. Acesso em: 18/04/2011.

_ Maps and figures, 2005. Disponível em: <http://www.fao.org/forestry/fra/41256/ en/>. Acesso em: 16/06/2011.

CENTRO DE ECONOMIA FLORESTAL APLICADA (CEFA). Oferta e demanda de madeira no estado do Paraná. Curitiba: SETI-FUNPAR-UFPR, 2007.

FOOD AND AGRICULTURE ORGANIZATION OF THE UNITED NATIONS (FAO). Vialle delle Terme di Caracalla. Rome, Italy, 1951. Disponível em: <www.fao.org/forestry>. Acesso em: 01/07/2011.

GFI. The Governance of Forests Initiative. A draft framework of indicators for assessing governance of the forest sector, 2009. Disponível em: 〈http://www.wri.org/gfi〉. Acesso em: 07/02/2011.

GRÖN. A. Howard. 1947. The economic foundations of forest politics. Unasylva, Vol. 1(3), n. 3. Disponível em: <www.fao.org/docrep/x5341e/x5341e00.htm - 6k>. Acesso em: 03/02/2011.

KISSLER, L.; HEIDEMANN, F. G. Governança pública: novo modelo regulatório para as relações entre Estado, mercado e sociedade? Rev. Adm. Pública, v. 40, n. 3. Rio de Janeiro, 2006.

MERLO, M.; PAVERI, M. Formación y ejecución de políticas forestales: un enfoque sobre la combinación de herramientas de políticas. FAO, XI Congresso Florestal Mundial. FAO. Antalya, 1997. Disponível em: <http://www.fao.org/forestry/docrep/wfcxi/PUBLI/V5/T32S/1.HTM>. Acesso em: 24/08/2011.

ORGANIZAÇÃO PARA COOPERAÇÃO E DESENVOLVIMENTO ECONÔMICO (OECD). Governance of State-Owned enterprises. Guidelines on the corporate. 2005. Disponível em: $<$ http://www.oecd.org>. Acesso em: 05/11/2010.

País Reforma. Divulgação Latino-americanos. Mesa Redonda sobre Governança Corporativa. Divisão de Assuntos Corporativos da OECD. 2005. Disponível em: <http://www.oecd.org>. Acesso em: 05/11/2010.

Painel Florestal. Paraná terá plano de desenvolvimento do setor florestal. 2011. Interact Comunicação Empresarial. Disponível em: 〈http://painelflorestal.com.br/noticias/florestas-lantadas/11612/parana-tera〉. Acesso em: 23/08/2011.

SANTOS, M. H. de C. Governabilidade, governança e capacidade governativa: algumas notas. Brasília, 1996. 
